\title{
Targeting Transforming Growth Factor- $\beta$ Signaling in Aortopathies in Marfan Syndrome
}

\author{
Daigo Sawaki, MD; Toru Suzuki, MD
}

$\mathbf{M}$ arfan syndrome (MFS) is characterized by mutations in the fibrillin-1 gene and dysregulation of transforming growth factor $-\beta$ (TGF $\beta$ ) signaling, which is phenotypically associated with gradual weakening of connective tissue throughout the body, including the lungs, bones and cardiovascular system. ${ }^{1}$ A primary cause of mortality in MFS patients reaching adolescence or adulthood is aortic rupture or dissection. Surgery is generally performed to remove the affected portion of the aorta, but more than half of patients who have had their aortas repaired require additional surgery or manifest aortic rupture because of expansion of the unrepaired regions of the aorta over time. ${ }^{2}$ At present, measures to identify patients exhibiting progressive expansion or re-expansion of the aorta after surgery is a topic of importance. On medical therapy, $\beta$-blockers have been historically used as the anchoring agent. The renin-angiotensin system (RAS) has also recently been implicated in the pathogenesis of Marfan aor- topathy, with initial experiments showing prevention of aortic root expansion in a mouse model of MFS using RAS blockade, ${ }^{3}$ which was followed by studies in human patients that showed similar results. ${ }^{4,5}$ These findings were welcomed with enthusiasm as a pharmacological solution for MFS, and have prompted several human clinical trials, which are presently ongoing to determine the possible benefit of RAS blockade in aortopathy in MFS patients. ${ }^{6}$ TGF $\beta$ signaling has also received attention as a key factor in the aortopathy of MFS patients, as not only the canonical regulatory pathway involving downstream Smad proteins but also a non-canonical pathway involving ERK and JNK kinases has been recently described as implicated in MFS pathology upon activation of the TGF $\beta$ pathway. ${ }^{7,8}$ Moreover, circulating levels of TGF $\beta$ have received attention because they are not only elevated in patients with MFS aortopathy but are also responsive to pharmacological treatment, thus suggesting their possible use as a sur-

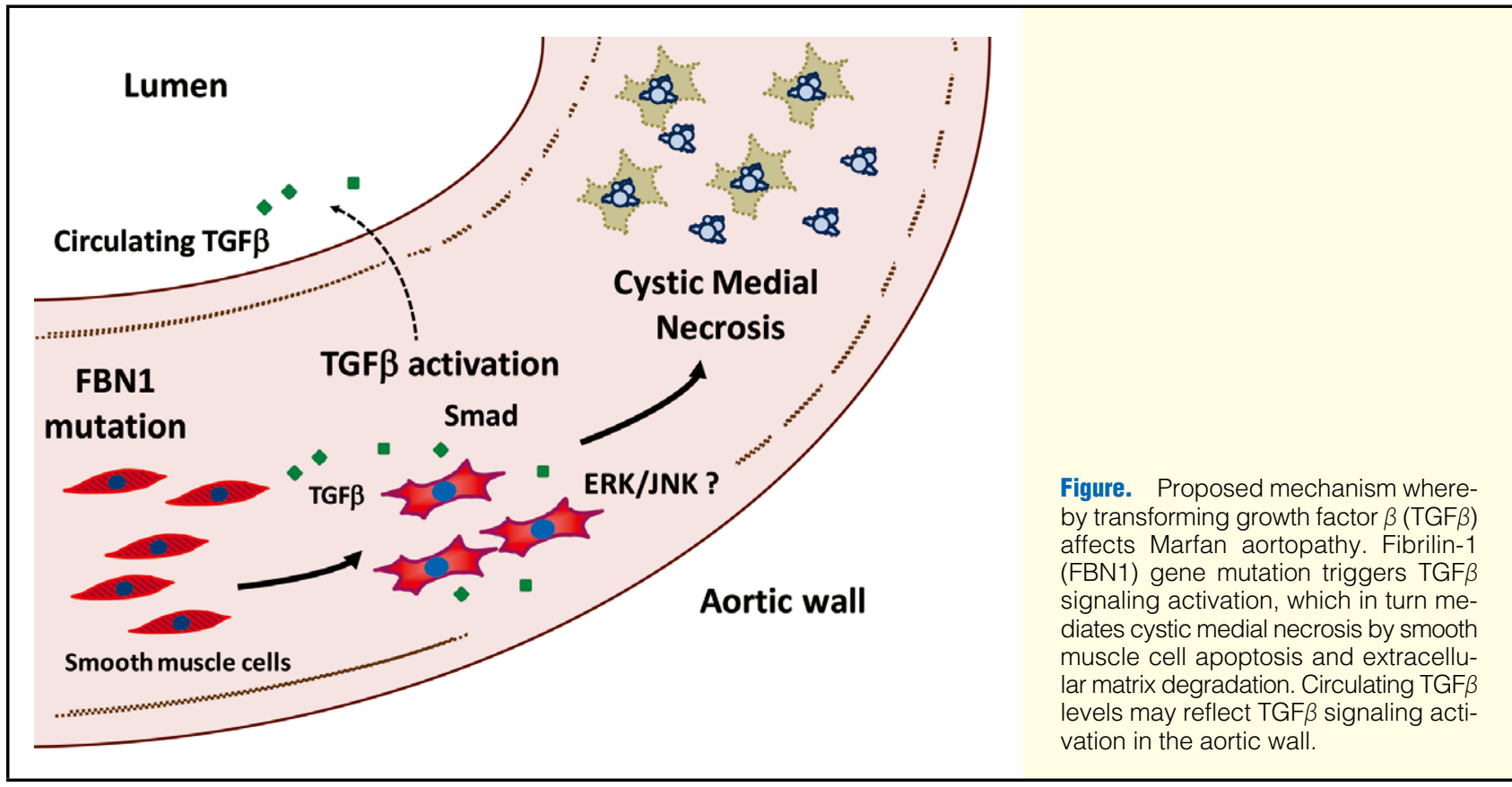

The opinions expressed in this article are not necessarily those of the editors or of the Japanese Circulation Society.

Received February 3, 2013; accepted February 3, 2013; released online February 14, 2013

Departments of Cardiovascular Medicine and Ubiquitous Preventive Medicine, The University of Tokyo, Tokyo, Japan

The authors contributed equally.

Mailing address: Toru Suzuki, MD, Department of Cardiovascular Medicine, Department of Ubiquitous Preventive Medicine, Graduate

School of Medicine, The University of Tokyo, 7-3-1 Hongo, Bunkyo-ku, Tokyo 113-8655, Japan. E-mail: torusuzu-tky@ umin.ac.jp

ISSN-1346-9843 doi:10.1253/circj.CJ-13-0183

All rights are reserved to the Japanese Circulation Society. For permissions, please e-mail: cj@j-circ.or.jp 
rogate biomarker for the aortic remodeling process. ${ }^{9}$ However, there remains a paucity of data linking the severity of aortic wall destruction, histologically increased focal TGF $\beta$ activation and elevated circulating TGF $\beta$ levels in human cases of Marfan aortopathy.

\section{Article p 952}

In this issue of the Journal, Kim and colleagues ${ }^{10}$ report on their investigation of aortic tissue injury, such as cystic medial degeneration and cellular apoptosis, and Smad 2 phosphorylation in MFS patients, in addition to TGF $\beta$ levels in both the peripheral blood and aortic tissue. They demonstrate an association between circulating levels of active TGF $\beta-1$ and the severity of aortic remodeling (cystic medial degeneration and Smad2 phosphorylation in aneurysmal aortic layers) in MFS patients.

One of the noteworthy features of this study is that, for the first time, an association between pathologic aortic remodeling and both TGF $\beta$ signaling in the aortic wall and circulating levels in MFS patients are shown (Figure). Activation of the Smad2 pathway had been previously reported as common to both syndromic and non-syndromic aneurysms of the human ascending aorta (including MFS as well as degenerative aneurysm and bicupsid aortic valve patients), but that previous study only reported pathologically increased Smad2 phosphorylation and expression levels of TGF $\beta$ in the diseased aortic wall and did not determine the association between these phenomena and the degree of aortic wall remodeling/ destruction or circulating TGF $\beta$ levels. ${ }^{11}$

Another feature of the present study is the patient cohort. Investigated patients had not been treated with antihypertensive drugs for more than 2 weeks, which provided the condition of minimal concomitant effects by the various drugs and agents used in this syndrome that may affect TGF $\beta$ signaling and MFS pathogenesis. This, however, does imply that patients were basically medically untreated and thus points to an unconventional cohort for present standards of care. Further, the authors report on the degree and relationship between Smad phosphorylation and TGF $\beta$ signaling at the histologic level in Asian subjects, as racial differences in MFS phenotype and circulating TGF $\beta$ levels had been reported. ${ }^{12}$ MFS patients with aortic dissection were also shown to exhibit more severe cystic medial degradation, and increased circulating or aortic TGF $\beta$ levels. Although this finding is descriptive and not necessarily causal, it describes an association between the severity of aortic remodeling and circulating TGF $\beta$ levels.

Several issues remain unanswered in the application, in the real world, of circulating TGF $\beta$ levels as a surrogate biomarker to monitor disease activity or therapeutic efficacy in MFS or other aortopathic patients, in addition to the technical difficulties that lead to false-positive results (eg, method of blood sampling). One is that it is still unclear is whether circulating TGF $\beta$ levels are truly associated with dilation of the aorta, which is of clinical importance. The present study showed a dilated aorta with an average width of $59 \mathrm{~mm}$ at the sinus of Valsalva regardless of circulating TGF $\beta$ levels. Lack of correlation between the $\mathrm{z}$ value (an indicator of aortic root expansion) and circulating TGF $\beta$ level, despite reduction in the level by pharmacological intervention, has also been reported. ${ }^{9}$ Another issue is the need to better understand the relative contribution of TGF $\beta$ and its downstream signaling molecules in aneurysmal formation in the Marfan aorta.

Collectively, circulating TGF $\beta$ levels may be associated with progression of aortic remodeling as reflected by activated Smad (phosphorylation) protein on histopathologic analysis. Importantly, however, other mechanisms, including Smadindependent pathways and/or inflammatory processes, might also contribute to clinical aneurysmal dilatation, rupture or dissection. ${ }^{13}$

\section{References}

1. Neptune ER, Frischmeyer PA, Arking DE, Myers L, Bunton TE, Gayraud B, et al. Dysregulation of TGF-beta activation contributes to pathogenesis in Marfan syndrome. Nat Genet 2003; 33: 407-411.

2. Kimura N, Tanaka M, Kawahito K, Itoh S, Okamura H, Yamaguchi A, et al. Early- and long-term outcomes after surgery for acute type a aortic dissection in patients aged 45 years and younger. Circ J 2011; 75: $2135-2143$.

3. Habashi JP, Judge DP, Holm TM, Cohn RD, Loeys BL, Cooper TK, et al. Losartan, an AT1 antagonist, prevents aortic aneurysm in a mouse model of Marfan syndrome. Science 2006; 312: 117-121.

4. Ahimastos AA, Aggarwal A, D'Orsa KM, Formosa MF, White AJ, Savarirayan R, et al. Effect of perindopril on large artery stiffness and aortic root diameter in patients with Marfan syndrome: A randomized controlled trial. JAMA 2007; 298: 1539-1547.

5. Brooke BS, Habashi JP, Judge DP, Patel N, Loeys B, Dietz HC 3rd. Angiotensin II blockade and aortic-root dilation in Marfan's syndrome. N Engl J Med 2008; 358: 2787-2795.

6. Lacro RV, Dietz HC, Wruck LM, Bradley TJ, Colan SD, Devereux $\mathrm{RB}$, et al. Rationale and design of a randomized clinical trial of betablocker therapy (atenolol) versus angiotensin II receptor blocker therapy (losartan) in individuals with Marfan syndrome. Am Heart J 2007; 154: $624-631$.

7. Holm TM, Habashi JP, Doyle JJ, Bedja D, Chen Y, van Erp C, et al. Noncanonical TGFbeta signaling contributes to aortic aneurysm progression in Marfan syndrome mice. Science 2011; 332: 358-361.

8. Habashi JP, Doyle JJ, Holm TM, Aziz H, Schoenhoff F, Bedja D, et al. Angiotensin II type 2 receptor signaling attenuates aortic aneurysm in mice through ERK antagonism. Science 2011; 332: 361-365.

9. Matt P, Schoenhoff F, Habashi J, Holm T, Van Erp C, Loch D, et al. Circulating transforming growth factor-beta in Marfan syndrome. Circulation 2009; 120: 526-532.

10. Kim KL, Yang JH, Song SH, Kim JY, Jang SY, Kim JM, et al. Positive correlation between the dysregulation of transforming growth factor- $\beta_{1}$ and aneurysmal pathological changes in patients with Marfan syndrome. Circ J 2013; 77: 952-958.

11. Gomez D, Al Haj Zen A, Borges LF, Philippe M, Gutierrez PS, Jondeau G, et al. Syndromic and non-syndromic aneurysms of the human ascending aorta share activation of the Smad2 pathway. $J$ Pathol 2009; 218: $131-142$.

12. Akutsu K, Morisaki H, Takeshita S, Ogino H, Higashi M, Okajima T, et al. Characteristics in phenotypic manifestations of genetically proved Marfan syndrome in a Japanese population. Am J Cardiol 2009; 103: $1146-1148$.

13. Radonic T, de Witte P, Groenink M, de Waard V, Lutter R, van Eijk $\mathrm{M}$, et al. Inflammation aggravates disease severity in Marfan syndrome patients. PloS One 2012; 7: e32963. 